\title{
Subject Identifier Primary Indicator
}

National Cancer Institute

\section{Source}

National Cancer Institute. Subject Identifier Primary Indicator. NCI Thesaurus. Code C94160.

Specifies whether this is the main or principal subject identifier. 